\title{
Article \\ Changes in Photosynthetic Pigments Content in Non- Transformed and AtCKX Transgenic Centaury (Centaurium erythraea Rafn) Shoots Grown under Salt Stress In Vitro
}

\author{
Milana Trifunović-Momčilov ${ }^{1, *(\mathbb{D})}$, Snežana Miloševićc ${ }^{1} \mathbb{D}$, Marija Marković $^{1}$, Marija Đurić $^{1}$ (D), \\ Slađana Jevremović ${ }^{1}$ (D) Ivana Č. Dragićević ${ }^{2} \mathbb{D}$ and Angelina R. Subotić ${ }^{1}$
}

1 Department for Plant Physiology, Institute for Biological Research "Siniša Stanković" —National Institute of Republic of Serbia, University of Belgrade, Bulevar Despota Stefana 142, 11060 Belgrade, Serbia; snezana@ibiss.bg.ac.rs (S.M.); marija.nikolic@ibiss.bg.ac.rs (M.M.); marija.djuric@ibiss.bg.ac.rs (M.Đ.); sladja@ibiss.bg.ac.rs (S.J.); heroina@ibiss.bg.ac.rs (A.R.S.)

2 Faculty of Biology, University of Belgrade, Studentski Trg 16, 11000 Belgrade, Serbia; dragicev@bio.bg.ac.rs

* Correspondence: milanag@ibiss.bg.ac.rs

Citation: Trifunović-Momčilov, M.; Milošević, S.; Marković, M.; Đurić, M.; Jevremović, S.; Dragićević, I.Č.; Subotić, A.R. Changes in Photosynthetic Pigments Content in Non-Transformed and AtCKX Transgenic Centaury (Centaurium erythraea Rafn) Shoots Grown under Salt Stress In Vitro. Agronomy 2021, 11 2056. https://doi.org/10.3390/ agronomy11102056

Academic Editor: Essaid Ait Barka

Received: 1 October 2021

Accepted: 8 October 2021

Published: 13 October 2021

Publisher's Note: MDPI stays neutral with regard to jurisdictional claims in published maps and institutional affiliations.

Copyright: (c) 2021 by the authors. Licensee MDPI, Basel, Switzerland. This article is an open access article distributed under the terms and conditions of the Creative Commons Attribution (CC BY) license (https:/ / creativecommons.org/licenses/by/ $4.0 /)$.

\begin{abstract}
The effects of graded sodium chloride $(\mathrm{NaCl})$ concentrations (0-, 50-, 100-, 150-, and 200-mM) on photosynthetic pigment contents in in vitro grown shoots of important medicinal plant species (Centaurium erythraea Rafn) were investigated. Non-transformed, one AtCKX1 and two AtCKX2 transgenic centaury lines, with altered cytokinin profiles, were used in this study. The chlorophyll $(\mathrm{Chl})$ and carotenoid contents differed in the non-transformed and transgenic lines. In general, salinity significantly reduced the $\mathrm{Chl} a$ and $\mathrm{Chl} b$ contents in comparison to the $\mathrm{NaCl}$-free medium. The lowest $C h l$ content was observed in AtCKX2 transgenic shoots grown on all the culture media. The total carotenoid content was increased in shoots of non-transformed and both AtCKX2 transgenic lines grown in $50-\mathrm{mM} \mathrm{NaCl}$. On the other hand, in concentrations $>50-\mathrm{mM} \mathrm{NaCl}$, the total carotenoid content was decreased in all analysed centaury shoots. The Chl $a / C h l b$ ratio in all the shoots increased progressively in the graded $\mathrm{NaCl}$ concentrations. Contrarily, the addition of $\mathrm{NaCl}$ in the culture medium reduced the $\mathrm{Chl} /$ carotenoid ratio in centaury shoots. Taken together, the results of this study partly explained the mode of centaury plant adaptations to salt stress in vitro. Thus, the results on centaury shoots confirmed that the determination of the photosynthetic pigment contents can be a very useful non-destructive screening method in order to discriminate susceptible and resistant plant species/lines to salt stress conditions.
\end{abstract}

Keywords: centaury; salinity; abiotic stress; AtCKX genes; chlorophyll; cytokinins

\section{Introduction}

Common centaury (Centaurium erythraea Rafn) belongs to the Gentianaceae family and represents an important medicinal plant species distributed throughout the Northern Hemisphere. In traditional medicine, centaury has for centuries been used to cure numerous health issues such as febrile conditions, blood sugar, anaemia, jaundice, gout, etc. [1] Centaury is a cosmopolitan plant species that inhabits mountain slopes, dry grasslands, and scrublands. In addition, centaury can also be found in saline soils.

Salinity is one of the most significant environmental stresses limiting cell metabolism and plant productivity [2]. The detrimental salinity effects on plants are the consequence of $\mathrm{Na}^{+}$and $\mathrm{Cl}^{-}$ion toxicity and, also, a water deficit that results in osmotic and ionic stress, which usually leads to numerous physiological and biochemical changes that inhibit plant growth, development, and protein synthesis [3]. Salinity stress induces remarkable alternations in physiological, biochemical, and molecular processes [4]. Photosynthesis is an important parameter used to monitor plant responses to abiotic stress. Reduced photosynthesis under salinity is not only attributed to stomata closure and reduced intercellular 
$\mathrm{CO}_{2}$ concentrations but, also, photosynthetic pigment photooxidation and photosynthetic enzymes activity, as well as chlorophyll $(\mathrm{Chl})$ and carotenoid contents due to oxidative stress [5,6]. Salt stress reduces the activity of enzymes involved in Chl synthesis and, at the same time, elevates the chlorophyllase activity, enhancing the Chl disorganisation [7,8]. It is known that $\mathrm{Chl}$ has an essential function in photosynthesis [9]. Recently, it has also been reported that salt stress has direct and indirect effects on the Chl content and photosynthetic efficiency [10]. The direct effects are referred to as the regulation of activity and expression levels of enzymes involved in Chl biosynthesis and photosynthesis, while the indirect effects are referred to as specific regulating pathways such as antioxidant enzymes.

During the time plants generally succeed in adapting to salinity by adjusting their $\mathrm{Chl}$ levels. The rate of change in the $\mathrm{Chl}$ content varies among different plant species. Even forty years ago, it was postulated that $\mathrm{NaCl}$ increased the activity of the Chl-degrading enzyme chlorophyllase, which resulted in a decreased total Chl content [11]. Later, it was also shown that, during salinity, the accumulation of ions affected the biosynthesis of different pigment fractions and, consequently, the reduced Chl content [12,13]. During the last decade, there has been a lot of literature data describing that salt stress caused the reduction of $C h l$ content in numerous plant species, such as corn [14], pumpkin [15], walnut [16], chili pepper [17], bean [18], melon [19], and Moldavian balm [20]. Accordingly, the decrement of the $\mathrm{Chl}$ content as a response to salt stress conditions can be considered as a general phenomenon that leads to the destruction of the chloroplast structure and instability of the pigment-protein complex and, finally, chlorosis in plants [21].

Besides the regulation of numerous developmental processes in plants, cytokinins (CKs) play an important role in the structural differentiation and biogenesis of chloroplasts and also induce the genes involved in chloroplast development [22-25]. Leaf senescence is a developmental process representing the final stage in the leaf life cycle or can also be initiated as a response to environmental stress conditions. Leaf senescence is characterised by the loss of Chl; leaf yellowing; and the degradation of proteins, membrane lipids, and RNA [26]. Determination of the reduced Chl amount in leaves can be very useful in the early detection of senescence.

Genetic transformation using specific CKX genes enabled the production of plants with an increased overexpression of transgenes and reduced levels of endogenous CKs [27-33]. The decreased amount of CKs is directly related to the increased activity of the catabolic enzyme cytokinin oxidase/dehydrogenase (CKX, EC 1.5.99.12), the only known enzyme involved in the catabolism of specific CKs to date. The individual members of the AtCKX gene family are expressed differentially [28]. In transgenic Arabidopsis plants, AtCKX1 expression was detected in the shoot apex, young flowers, and in the roots. On the other hand, the expression of the AtCKX2 promoter was detected in the shoot apex while no AtCKX2 expression was observed in Arabidopsis roots [28]. It is also known that AtCKX proteins have different subcellular localisations. AtCKX1 is a mitochondrial protein, and the final destination of AtCKX1 is the vacuole. AtCKX2 represents the peptide for targeting the endoplasmic reticulum and subsequent transport to the extracellular region [28]. Plants with 'cytokinin deficiency syndrome' showed decreased apical dominance and shoot growth, reduced leaf size, delayed flowering, and also, a reduced number of flowers. Considering that the senescence-delaying effect of CKs is well-known, it was suggested that these plant hormones are key components in the regulation of leaf senescence [34]. Accordingly, it can be assumed that specific transformants with reduced endogenous CK levels could represent very useful tools in the investigation of photosynthetic pigment contents and senescence, ultimately.

The salinity stress response of centaury species grown in vitro is described in a few literature data summarized in Reference [35]. Considering common centaury, there have been only two reports about the salinity stress response. Šiler et al. [36] described the effects of salinity on the in vitro growth and photosynthesis of centaury shoots. Recently, Trifunović-Momčilov et al. [37] showed the physiological and biochemical aspects of the salinity stress response of non-transformed and AtCKX transgenic centaury shoots and 
roots grown in vitro. It was shown that centaury roots showed a higher salinity tolerance compared to shoots. Considering the fact that maintaining the Chl content contributes to a salt tolerance, in this study, we investigated the influence of salinity in vitro on the photosynthetic pigments of non-transformed and AtCKX transgenic centaury shoots with a reduced amount of bioactive CKs.

\section{Materials and Methods}

\subsection{Plant Material, Growth Media, and Culture Conditions}

Non-transformed and transgenic AtCKX centaury plants were obtained as previously described [38]. One AtCKX1 (line 29) and two AtCKX2 (lines 17 and 26) transgenic centaury lines were selected as the starting plant materials. The selection of these three transgenic lines was based on the previously described overexpression of AtCKX genes in centaury shoots and roots, which resulted in an altered CKs profile, leading to a decline of the bioactive CK levels and, at the same time, increased contents of storage CK forms, inactive $\mathrm{CK}$ forms, and/or CK nucleotides [32]. The shoots of non-transformed and transgenic AtCKX lines were grown in vitro on half-strength plant growth regulator-free MS medium (1/2MS [39]) solidified with 0.7\% agar (Torlak, Belgrade, Serbia) and supplemented with 3\% sucrose and 100-mg L ${ }^{-1}$ myo-inositol (Sigma-Aldrich, St. Louis, MO, USA). Four weeks after the last subculture, isolated centaury shoots of the non-transformed and all the transgenic AtCKX lines were grown on new 1/2MS plant growth regulator-free medium or $1 / 2 \mathrm{MS}$ medium supplemented with a range of $\mathrm{NaCl}$ (Lach-Ner, Neratovice, Czech Republic) concentrations (50-, 100-, 150-, and 200-mM) during the next eight weeks. The medium was adjusted to $\mathrm{pH} 5.8$ with $\mathrm{NaOH} / \mathrm{HCl}$ and autoclaved at $121^{\circ} \mathrm{C}$ for $25 \mathrm{~min}$. All in vitro cultured plants were grown at $25 \pm 2{ }^{\circ} \mathrm{C}$ and at a 16-h/8-h photoperiod ('Tesla' white fluorescent lamps, $65 \mathrm{~W}, 4500 \mathrm{~K}$; light flux of $47 \mu \mathrm{mols}^{-1} \mathrm{~m}^{-2}$ ). The experiments were repeated three times, with 90 explants per each treatment.

\subsection{Quantification of Photosynthetic Pigments}

The isolation of the $\mathrm{Chl}$ and carotenoids was accomplished from the leaves of nontransformed and AtCKX transgenic centaury shoots after eight weeks of cultivation. Pigment extraction was done from leaves collected in the bottom part of the rosette. The total $\mathrm{Chl}$ and carotenoid contents were extracted using $96 \%$ ethanol. The plant material was heated in a water bath at $70{ }^{\circ} \mathrm{C}$. The absorbance of the pigments was further measured with a UV-visible spectrophotometer (Agilent 8453, Life Sciences, Santa Clara, CA, USA) at 470, 648 , and $664 \mathrm{~nm}$. The concentrations of $\mathrm{Chl} a, \mathrm{Chl} b$, and the carotenoids were calculated using the equations proposed by Lichtenthaler [40]:

$$
\begin{aligned}
& \text { Chl } a(\mu \mathrm{g} / \mathrm{g})=13.36 \times A_{664}-5.19 \times A_{648} / \mathrm{FW} \\
& \operatorname{Chlb}(\mu \mathrm{g} / \mathrm{g})=27.43 \times A_{648}-8.12 \times A_{664} / \mathrm{FW} \\
& \text { Carotenoids }(\mathrm{x}+\mathrm{c})(\mu \mathrm{g} / \mathrm{g})=\left(1000 \times A_{470}-2.13 \times \mathrm{C}_{\mathrm{a}}-97.64 \times \mathrm{C}_{\mathrm{b}}\right) / 209 / \mathrm{FW}
\end{aligned}
$$

The Chl $a / C h l b$ ratio was calculated from the quotient of $C h l a$ and $C h l b\left(C_{\mathrm{a}} / \mathrm{C}_{\mathrm{b}}\right)$, while the $\mathrm{Chl} /$ carotenoids ratio was calculated from the quotient of their total values $\left(\mathrm{C}_{(\mathrm{a}+\mathrm{b})} / \mathrm{C}_{(\mathrm{x}+\mathrm{c})}\right)$. Determination of the photosynthetic pigments was accomplished in three biological samples per those non-transformed and each of the transgenic lines. Additionally, the absorbance of the supernatant was measured three times for each sample. The concentrations of all the analysed photosynthetic pigments were presented as $\mu \mathrm{g} / \mathrm{g}$ of fresh sample weight (FW).

\subsection{Statistical Analysis}

The effect of a range of $\mathrm{NaCl}$ concentrations $(0-200 \mathrm{mM})$ on the photosynthetic pigment contents of 8-week-old non-transformed and transgenic AtCKX shoots were evaluated using a standard two-factor analysis of variance (ANOVA). The results were presented as 
the mean \pm SE. The comparisons between the mean values were made using Fisher's LSD (least significant difference) post-hoc test calculated at a confidence level of $p \leq 0.05$.

\section{Results}

\subsection{Effect of $\mathrm{NaCl}$ on Photosynthetic Pigments Content of Centaury Shoots Grown In Vitro}

The shoots of non-transformed and three transgenic AtCKX lines successfully survived eight weeks on $1 / 2 \mathrm{MS}$ medium supplemented with a range of $\mathrm{NaCl}$ concentrations $(0-, 50-, 100-, 150-$, and 200-mM). The morphological appearance of the shoots in the non-transformed and AtCKX lines grown on $\mathrm{NaCl}$-free medium showed normal rosette morphology and oval leaves with dark green colour. However, salt stress deteriorated the phenotypic appearances in all the salt-treated centaury shoots (Figure 1). Cultivation of centaury shoots in increased salt-enriched mediums caused the rolling and burning of the leaf tips and yellowing of the whole plant. With an increase of the $\mathrm{NaCl}$ concentrations in the culture media, the profiles of the leaves evolved from green to lighter tones. In addition, most yellow leaves with altered morphology were observed on shoots grown in culture media supplemented with $150-$ and $200-\mathrm{mM} \mathrm{NaCl}$. The chlorosis of leaves is one of the most common symptoms of salt stress in plants due to the decreasing amounts of photosynthetic pigments. In the common centaury cultures, chlorosis reached higher levels with the increased $\mathrm{NaCl}$ concentrations. The highest level of chlorosis at the highest salinity rate (200-mM) in both the non-transformed and transgenic lines was observed. Visible leaf damage was detected in all the centaury lines, but the leaves of the ATCKX2-26 line exhibited drastic senescence symptoms, as indicated by the intense necrotic areas in the leaves (Figure 1). Moreover, it was interesting to note that the non-transformed and all the AtCKX transgenic centaury shoots spontaneously rooted in $\mathrm{NaCl}$-free and the medium supplemented only with $50-\mathrm{mM} \mathrm{NaCl}$ after eight weeks.
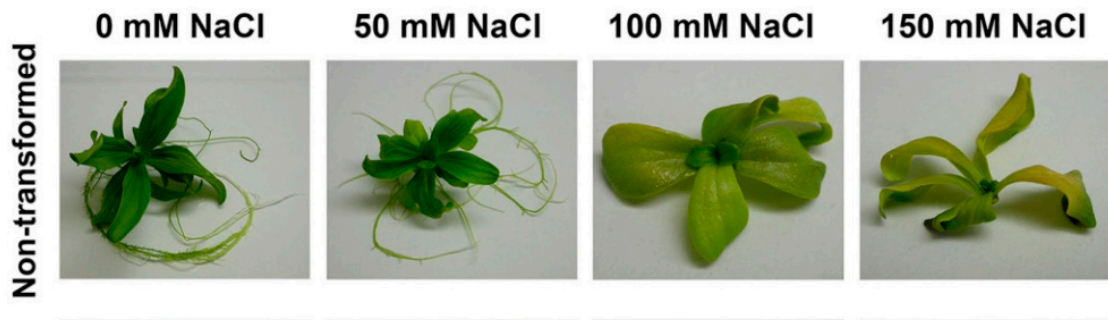

\section{$200 \mathrm{mM} \mathrm{NaCl}$}
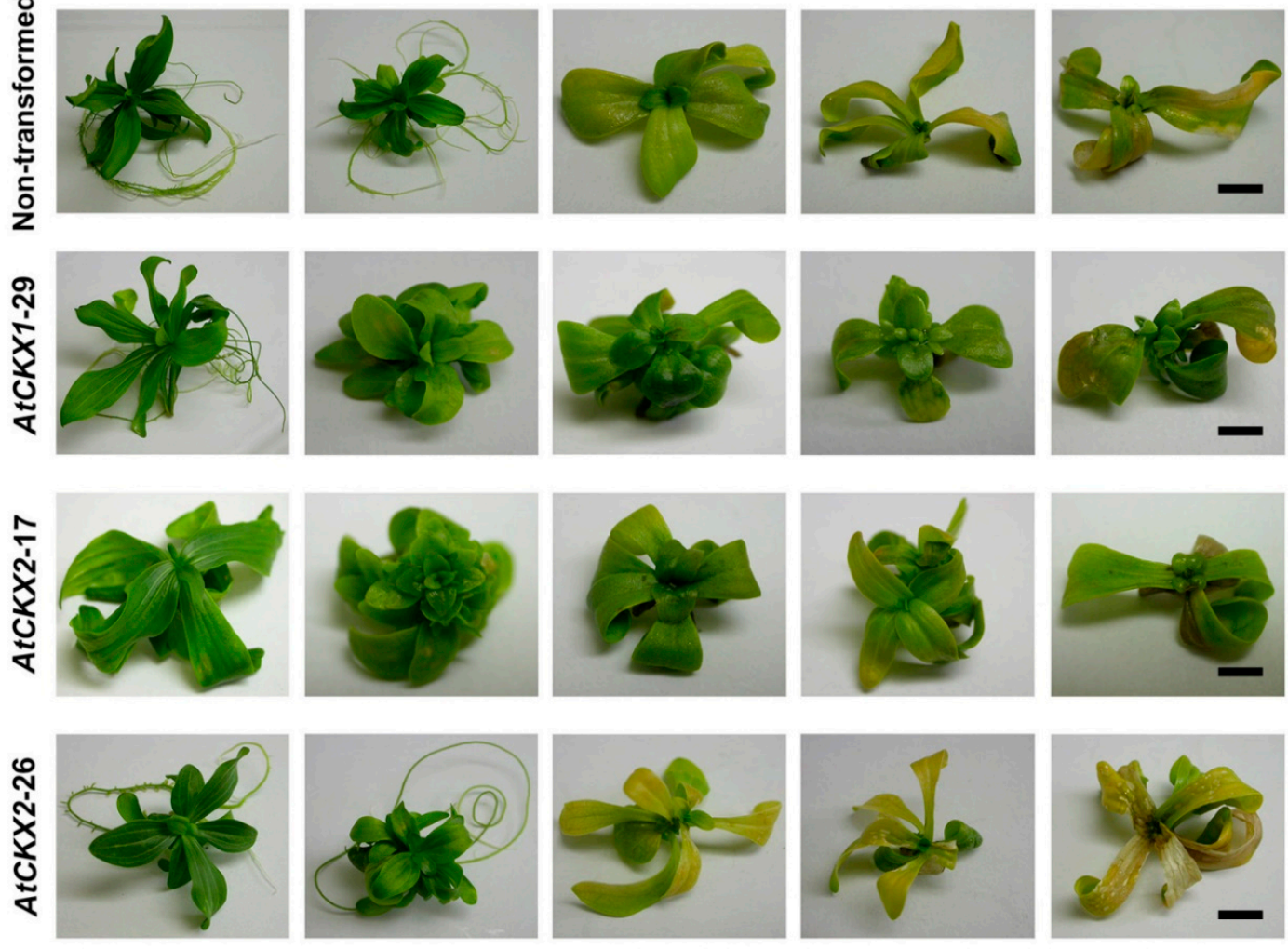

Figure 1. Eight-week-old non-transformed and AtCKX transgenic Centaurium erythraea shoots grown in 1/2MS medium supplemented with a range of $\mathrm{NaCl}$ concentrations (0-mM, 50-mM, 100-mM, 150-mM, and 200-mM). Bars indicate $10 \mathrm{~mm}$. 
The total Chl $(C h l a+C h l b)$ content is shown in Figure 2a. It was evident that the biosynthesis of $\mathrm{Chl}$ in common centaury was altered and affected by the salinity stress. When the shoots were grown in $\mathrm{NaCl}$-free medium, significant differences in the total Chl content between the non-transformed and transgenic AtCKX lines were observed. In the non-transformed and transgenic line AtCKX1-29, the total Chl content was similar in the shoots grown in $\mathrm{NaCl}$-free medium, while the total $\mathrm{Chl}$ contents in both AtCKX2 transgenic lines varied greatly. One transgenic line $A t C K X 2-26$ had a significantly higher total $C h l$ content in comparison to the non-transformed shoots and transgenic line AtCKX1-29. A higher total $\mathrm{Chl}$ content in this transgenic line was the consequence of a higher content of $C h l b$, which was detected in this line in comparison to all the other shoots (Figure 2c). Contrarily, the other AtCKX2 transgenic line (17) showed a several times lower total Chl content when the shoots were grown in the $\mathrm{NaCl}$-free medium. Regarding the response to salinity, all the analysed centaury shoots showed different patterns. In the non-transformed shoots and transgenic lines AtCKX1-29 and AtCKX2-26, a decreased total Chl content started with a slight salinity application $(50-\mathrm{mM} \mathrm{NaCl})$. Contrarily, in transgenic line AtCKX2-17, a significant decrement of the total $\mathrm{Chl}$ content was observed in shoots grown in a two-times higher $\mathrm{NaCl}$ concentration (100-mM). Although the same trend of Chl degradation was noticed in all the analysed centaury lines, significant differences were detected. The total Chl content was decreased in all the AtCKX transgenic lines in 150- and $200-\mathrm{mM} \mathrm{NaCl}$ in comparison to the non-transformed shoots.
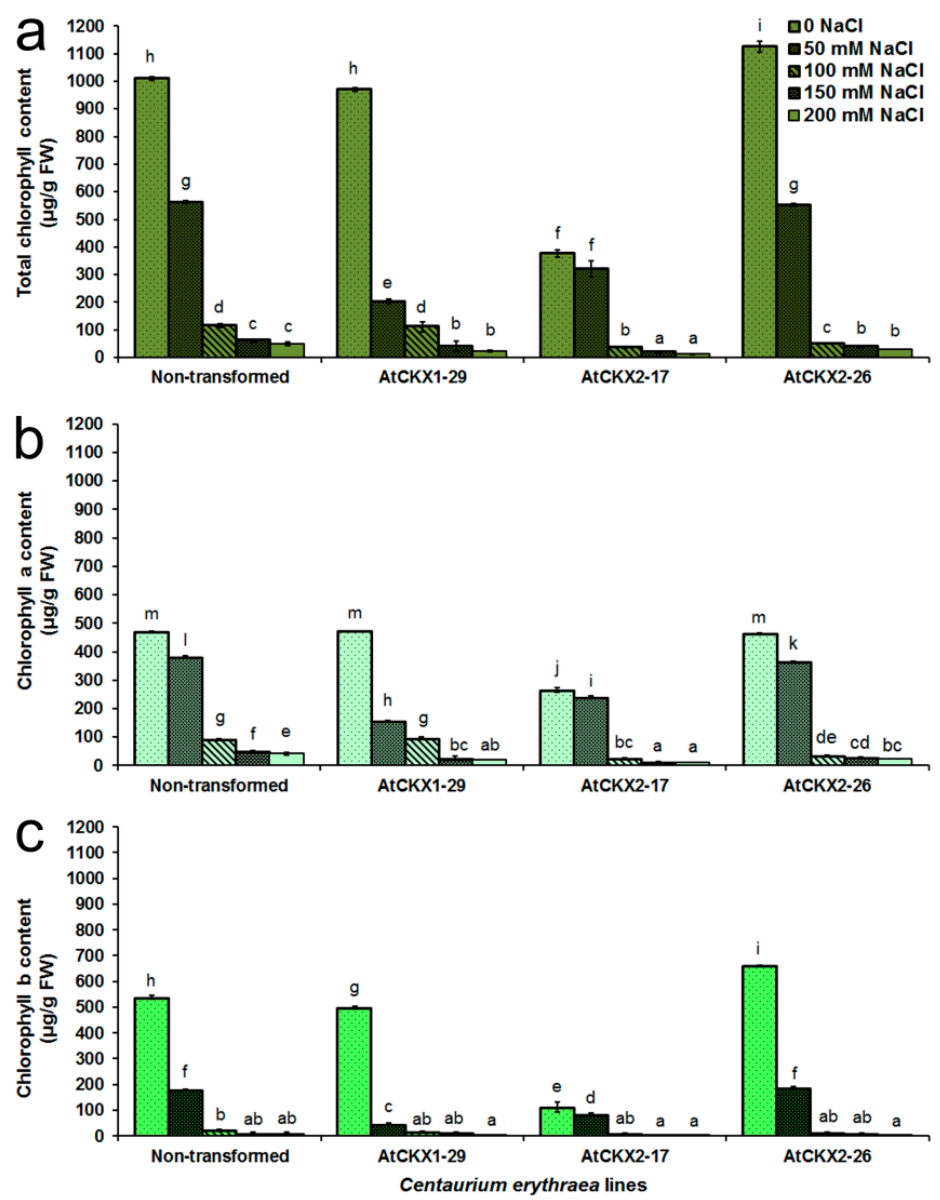

Figure 2. Total Chl (a), Chl a (b), and Chl b (c) contents in the shoots of non-transformed and transgenic centaury lines (AtCKX1-29, AtCKX2-17, and AtCKX2-26) after 8 weeks of growth on 1/2MS medium supplemented with $0-, 50-, 100-, 150-$, and $200-\mathrm{mM} \mathrm{NaCl}$. The data represent the mean \pm standard error. Means marked with a different letter are significantly different from the control, according to the LSD test $(p \leq 0.05)$. 
The effect of salinity on Chl $a$ and Chl $b$ was separately analysed (Figure 2b,c). Different patterns in the decrement of Chl $a$ in the non-transformed and transgenic $A C K X$ shoots were observed. A rapid decrement in the Chl a content was observed at concentrations $>100-\mathrm{mM}$ in the shoots of non-transformed and both AtCKX2 transgenic lines, while, in the shoots of the AtCKX1-29 transgenic line, a significant decrement of the Chl a content was detected even in 50-mM NaCl. Regardless of the initial values, the Chl a content continued to decrease until $200-\mathrm{mM} \mathrm{NaCl}$ in all the analysed centaury shoots. It was interesting to note that, as in the case of the total Chl content, the Chl a content was decreased in all the AtCKX transgenic lines in 150 - and $200-\mathrm{mM} \mathrm{NaCl}$ in comparison to the non-transformed shoots. The alteration of the $\mathrm{Chl} b$ content was also noticed in centaury shoots under salinity conditions. When the $\mathrm{NaCl}$ concentration in the medium increased, the $\mathrm{Ch} b$ content in the shoots was accordingly decreased. The content of $C h l b$ in the shoots of the non-transformed and transgenic lines greatly varied. In the non-transformed and AtCKX2-26 transgenic line, the similar $\mathrm{Chl} b$ contents in the shoots grown at $50-\mathrm{mM}$ of $\mathrm{NaCl}$ were determined, while, in the other concentrations, a significantly rapid decrement was observed. The smallest $\mathrm{Chl}$ $b$ content was detected in $200-\mathrm{mM} \mathrm{NaCl}$ in all the centaury shoots.

The total carotenoid content was evaluated in all the centaury shoots (Figure 3). It is evident that the total carotenoid content was different in the transgenic lines in comparison to the non-transgenic line when they were grown in the $\mathrm{NaCl}$ medium. When the non-transformed and $A t C K X 2$ transgenic lines were grown in $\mathrm{NaCl}$-free medium, a similar total carotenoid content was observed, while, in the AtCKX1 transgenic line, the carotenoid content was significantly lower. Additionally, the same pattern was recorded in slightly saline conditions. In $50-\mathrm{mM} \mathrm{NaCl}$, the total carotenoid content was increased in the non-transformed shoots and AtCKX2 transgenic lines in comparison to the $\mathrm{NaCl}$ free medium. In the $A t C K X 1$ transgenic shoots, the total carotenoid content remained unchanged. Further, in $100-\mathrm{mM} \mathrm{NaCl}$, the total carotenoid content continued to decrease slowly in the non-transformed and AtCKX1 shoots, while, in the AtCKX2 transgenic shoots, a more rapid decrease in the total carotenoid content was observed. In comparison to the non-transformed shoots, in all the AtCKX transgenic lines, the most decreased total carotenoid content was detected in $150-$ and $200-\mathrm{mM} \mathrm{NaCl}$.

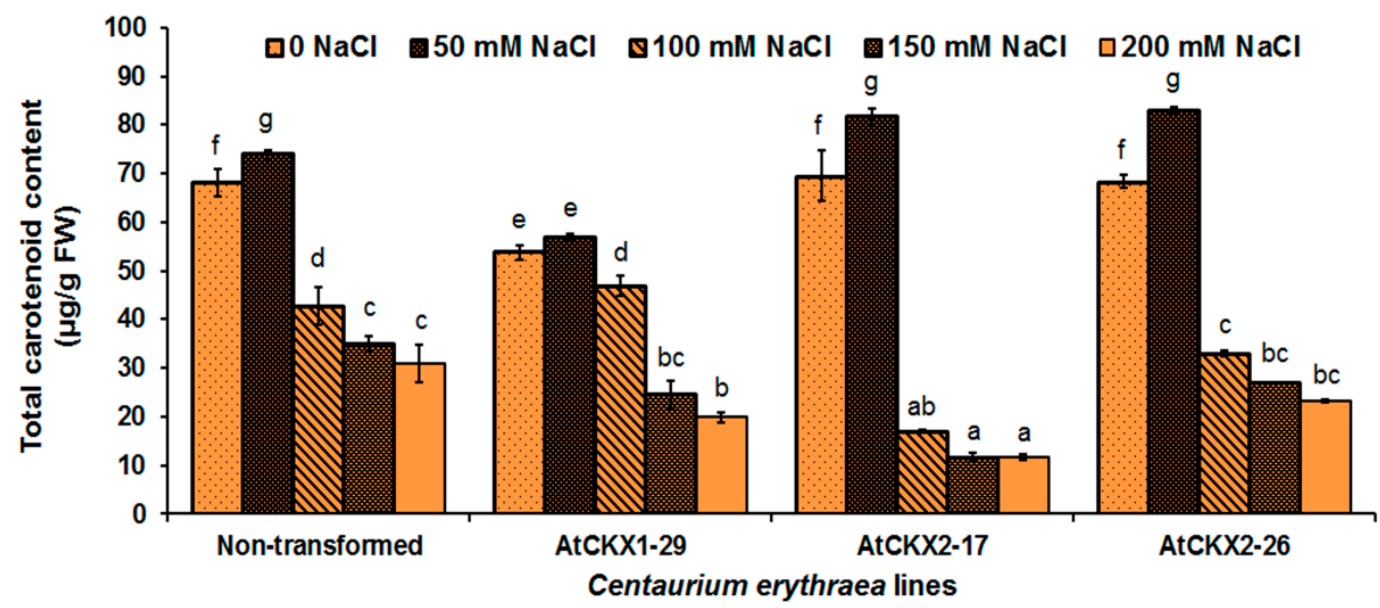

Figure 3. The total carotenoid content in the shoots of non-transformed and transgenic centaury lines (AtCKX1-29, AtCKX217, and $A t C K X 2-26$ ) after 8 weeks of growth on 1/2MS medium supplemented with 0-, 50-, 100-, 150-, and $200-\mathrm{mM} \mathrm{NaCl}$. The data represent the mean \pm standard error. Means marked with a different letter are significantly different from the control, according to the LSD test $(p \leq 0.05)$. 


\subsection{Effect of $\mathrm{NaCl}$ on Photosynthetic Pigments Ratio}

The evaluation of the Chl $a / C h l b$ ratio of the common century non-transformed and $A t C K X$ transgenic lines is shown in Figure 4. The non-transformed and transgenic lines showed different $\mathrm{Chl} \mathrm{a} / \mathrm{Chl} b$ ratios in the shoots grown, even those grown in the $\mathrm{NaCl}$ free medium. The non-transformed and two transgenic centaury lines (AtCKX1-29 and AtCKX2-26) showed similar Chl a/Chl b ratios, while, in transgenic line AtCKX2-17, an almost doubled $\mathrm{Chl} a / \mathrm{Chl} b$ ratio was noticed when the shoots were grown in $\mathrm{NaCl}$-free medium. Regardless of the $\mathrm{NaCl}$, an incremental increase in the nutrition medium in the $\mathrm{Chl} a / \mathrm{Chl} b$ ratios in all the analysed centaury lines was observed. In shoots grown in $200-\mathrm{mM} \mathrm{NaCl}$, the highest Chl a/Chl $b$ ratio was determined in the non-transformed and AtCKX1-17 and AtCKX2-29 transgening lines. The lowest change in the Chl $a / C h l b$ ratio under salinity stress was achieved in the AtCKX2-26 transgenic line.

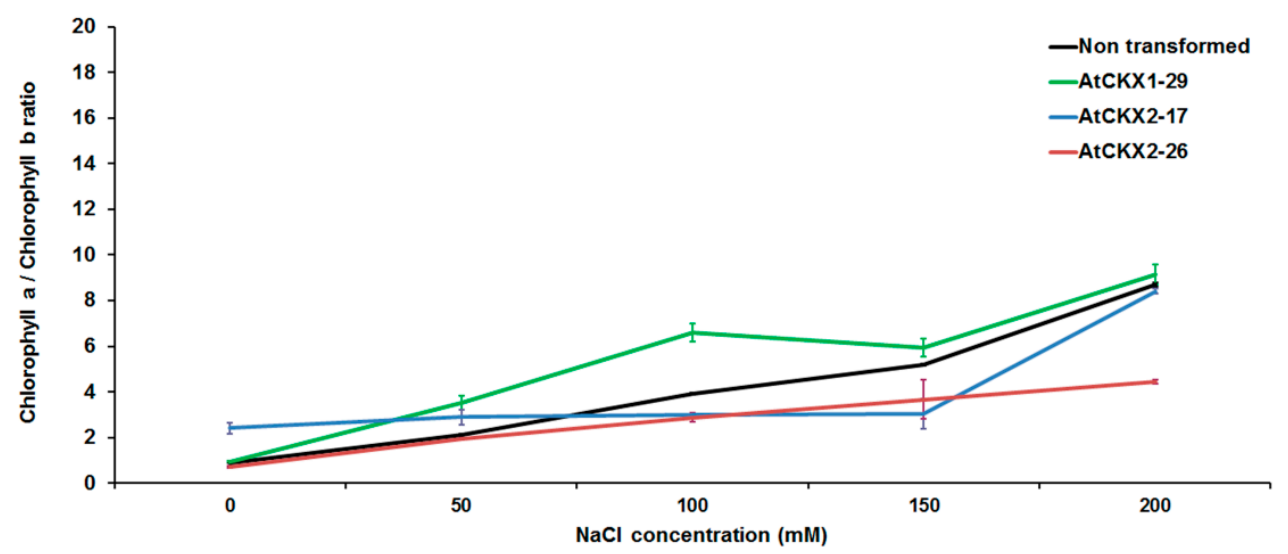

Figure 4. Chl $a$ and Chll $b$ ratio in the shoots of non-transformed and transgenic centaury lines (AtCKX1-29, AtCKX2-17, and AtCKX2-26) after 8 weeks of growth in 1/2MS medium supplemented with $0-, 50-, 100-, 150-$, and $200-\mathrm{mM} \mathrm{NaCl}$. The data represent the mean \pm standard error. Means marked with a different letter significantly different from the control, according to the LSD test $(p \leq 0.05)$, are presented in Supplementary Materials.

The ratio of the total $\mathrm{Chl}$ and total carotenoids determines the level of plant senescence. The obtained results in our study showed a different total $\mathrm{Chl} /$ carotenoid ratio in the non-transformed and transgenic lines (Figure 5). As in the case of the Chl a/Chl b ratio, when the non-transformed and two transgenic centaury lines (AtCKX1-29 and AtCKX2-26) are grown in a NaCl-free medium, a similar total $\mathrm{Chl} /$ total carotenoids ratio was detected. In the same medium, transgenic line AtCKX2-17 showed about a three times lower initial total $\mathrm{Chl} /$ total carotenoids ratio than the non-transformed and other transgenic lines. The addition, the $50-\mathrm{mM} \mathrm{NaCl}$ medium remarkably reduced the total $\mathrm{Chl} /$ total carotenoids ratio in the non-transformed (14.84 $\rightarrow 7.61)$, AtCKX1-29 (18.05 $\rightarrow 3.56)$, and AtCKX2-26 $(16.49 \rightarrow 6.66)$ transgenic shoots, while, in the shoots of AtCKX2-17, the reduction was lower $(5.59 \rightarrow 3.94)$. It is obvious that a significant reduction of the $\mathrm{Chl} /$ total carotenoids ratio was detected in the transgenic centaury lines with regards to the non-transformed line. The reduction of the $\mathrm{Chl} /$ total carotenoid ratio was further continued in $100-\mathrm{mM}$ $\mathrm{NaCl}$ and maintained at a similar level in $150-$ and $200-\mathrm{mM} \mathrm{NaCl}$ in all the centaury lines. 


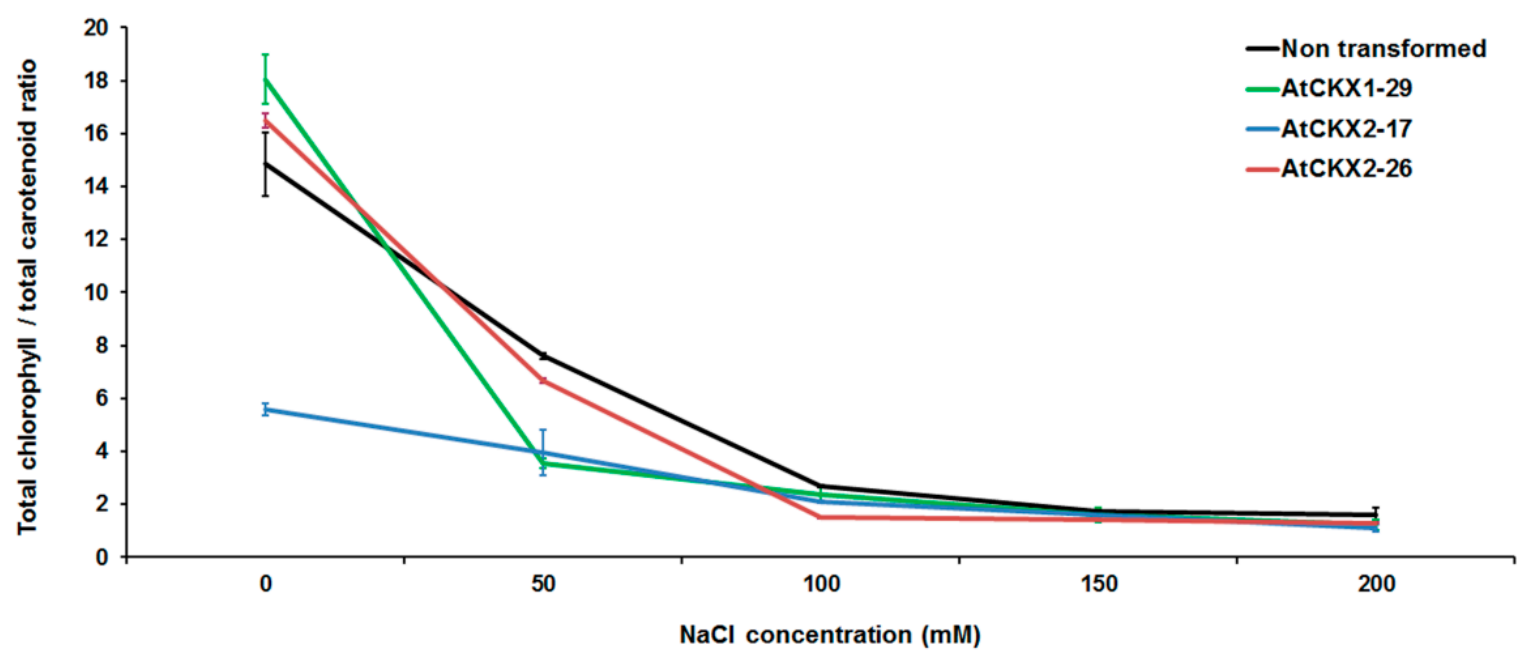

Figure 5. The total $\mathrm{Chl}$ and total carotenoid ratio in the shoots of non-transformed and transgenic centaury lines (AtCKX1-29, AtCKX2-17, and AtCKX2-26) after 8 weeks of growth in 1/2MS medium supplemented with 0-, 50-, 100-, 150-, and 200-mM $\mathrm{NaCl}$. The data represent the mean \pm standard error. Means marked with a different letter significantly different from the control, according to the LSD test $(p \leq 0.05)$, are presented in Supplementary Materials.

\section{Discussion}

In this study, we postulated that a reduced amount of bioactive CKs in AtCKX transgenic centaury plants could alter the photosynthetic pigment contents in shoots grown under salt stress in vitro. There is a lot of evidence in the literature that the phenomenon of senescence is also regulated by CKs [41] and reducing the Chl content represents one of the significant senescence markers [42-45]. It is also known that salt stress causes progressive Chl degradation, which leads to a reduced light absorption in plant leaves [5,46-48]. The results of this work showed that, in the transgenic AtCKX2-17 shoots, an almost three times lower total $\mathrm{Chl}$ content was observed in comparison to the non-transformed shoots. Thus, it can be assumed that a reduced amount of cytokinin speeds up senescence. On the other hand, a total Chl content similar to that in the non-transformed shoots was determined in the transgenic line AtCKX1-29, while a significantly higher total Chl content was observed in AtCKX2-26. An increased total Chl content was also obtained in the transgenic AtCKX2 tobacco line, where the leaves remained green longer than the control leaves, which turned yellow faster. In addition, it was observed that the amount of total Chl in the transgenic tobacco leaves decreased during the time [49]. Despite our theoretical expectations, the transgenic AtCKX leaves of Arabidopsis thaliana also did not show accelerated senescence [28]. Some previous investigations also showed that an increased CKX activity in senescing barley [50] and a high expression of the CKX genes throughout the senescence in Trifolium repens [51] support our findings that CKX genes in fact do not induce senescence but facilitate the progression of senescence. Ciobanu and Sumalan [52] reported that the tomato $\mathrm{Chl}$ content decreased with an increasing salinity, and the changes in the Chl content of the leaves occurred barely after a prolonged growth of six weeks. The modulation of the photosynthetic performance in Pennisetum leaves under long-term moderate salinity stress also involved the inhibition of leaf pigment synthesis [53].

Soil salinity and saline habits, as well as arid climates, greatly affect the synthesis of plant pigment components [54]. In general, the decrement of photosynthetic pigment contents under salt stress is considered to be a result of the slow synthesis or fast breakdown of pigments [55]. In all the centaury shoots, decreased Chl $a$ and $C h l b$, as well as the total $\mathrm{Chl}$ content in increased $\mathrm{NaCl}$ concentrations in the culture medium, were recorded. These results are in accordance with a previous work, which reported that salt stress induced with $\mathrm{NaCl}$ caused a decrement in the total Chl content in Phaseolus vulgaris [56], Catharanthus roseus [57], Vigna unguiculata [58], Vigna subterranean [59], Ocimum basilicum [60], and Solanum lycopersicum [61]. Recent research showed that salinity significantly decreased the 
Chl content and photosynthetic efficiency of sweet sorghum [62] and peppermint plants [63]. It was also reported that $\mathrm{Chl} a, \mathrm{Chl} b$, and the total Chl content in centaury leaves decreased with the increment of the salt concentration [36]. The reduction of Chl under salt stress could be attributed to the increased activity of photosynthetic enzymes and instability of the pigment-protein complex [5,64-66]. Khan [67] also reported that saline stress slowed the production of the photosynthetic pigments. The reduction of the total carotenoid content was observed in all the centaury shoots cultured in mediums supplemented with $>50-\mathrm{mM} \mathrm{NaCl}$. The obtained results agreed with those reported in Hordeum vulgare [68], Salvinia molesta [69], Cornus sericea [70], and melons [19]. Salt stress induced the degradation of $\beta$-carotene, which further resulted in a decreased carotenoid content [71]. Carotenoids are integrated constituents of thylakoid membranes, and they absorb and transfer light to $\mathrm{Chl}$ and, thus, protect $\mathrm{Chl}$ from photooxidation [72]. Accordingly, the degradation of carotenoids might cause $\mathrm{Chl}$ degradation as well. The degradation of photosynthetic pigments under salinity is probably the consequence of increased toxic ions, enhanced chlorophyllase enzyme activity, and the damaging of the photosynthetic apparatus [20]. Recent research showed that a high level of toxic ions originating from different salts in wastewater induced the loss of photosynthetic pigments, including Chl $a, \mathrm{Chl} b$, and carotenoids in wheat [73]. Considering that salinity caused an altered photosynthetic pigment metabolism, it is clear that the $\mathrm{Chl}$ content is strictly regulated under abiotic stress [7].

Chl $a$ is present in the reaction centres of photosystem I and II, while Chl $b$ is present exclusively in the pigment antenna system [74]. The weight of the Chl $a / C h l b$ ratio is an important indicator of the photosynthetic apparatus adaptation to the light conditions [75]. The Chl $a / C h l b$ ratio in dicotyledonous plants is usually 3:1 [76]. In the present study, there was a tendency toward an increased $C h l a / C h l b$ ratio with the increased salinity level in all the analysed centaury shoots. In the non-transformed shoots, in the range of the $\mathrm{NaCl}$ concentrations, the Chl $a / C h l b$ ratio ranged between 0.88 and $8.72 \mu \mathrm{g} / \mathrm{g} \mathrm{FW}$; in transgenic line AtCKX1-29, the detected ratio was 0.95-9.14; in AtCKX2-17, 2.41-8.40; and in AtCKX2-26, 0.71-4.45. An increased Chl a/Chl $b$ ratio was also observed in the control and transgenic AtCKX2 leaves of tobacco [49]. Additionally, salt stress increased the Chl $a / C h l b$ ratio in pepper [77]. During the process of Chl degradation, Chl $b$ is converted to $C h l a$, and this might explain the increment of the Chl $a / C h l b$ ratio [78]. Traditionally, the sun-shaded tolerance in plants has been defined based on the Chl $a / C h l b$ ratio $[79,80]$. The $C h l$ a / Chl b ratio has variable values, and when the ratio is $\sim 3$, it is clear that plants are adapting to the light conditions. The plants species living in the shadow showed Chl $a / C h l b$ ratios lower than in the sun-exposed plants [40]. Thus, a decrease in the $\mathrm{Chl} a / \mathrm{Chl} b$ ratio might be interpreted as an enlargement of photosystem II. Considering that Chl $a$ is placed in photosystem I and II, it can be supposed that Chl $a$ is probably primarily degraded during senescence. A stronger decrement of the Chl a content in comparison to $C h l b$ and, accordingly, a reduced $C h l a / C h l b$ ratio was also observed during leaf senescence in Hordeum vulgare leaves [81] and during dark-induced senescence in Cucurbita pepo cotyledons [82]. Previous investigations have also demonstrated darknessinduced cotyledon senescence in Arabidopsis seedlings [83]. Furthermore, it was indicated that CKs could serve as a regulatory mechanism coordinating senescence in individually darkened cotyledons [84]. Additionally, the in vitro culture conditions, although constantly controlled, enable light flux alterations in comparison to nature, and plants need to adapt to lowered light conditions. Thus, the ability of the whole plant to control the senescence progression underlies the coordination of senescence progression in individual leaves.

The weight ratio of the total $C h l$ and total carotenoids is an indicator of the greenness of plants [40]. In a natural habitat, the $\mathrm{Chl} /$ carotenoids ratio is normally between 4.2 and 5 in leaves of sun-exposed plants and between 5.5 and 7.0 in leaves of shade-exposed plants. Lower values of the Chl/carotenoids ratio represent an indicator of the damage of the plant photosynthetic apparatus, which is expressed by a faster breakdown of Chl than carotenoids. Leaves with a Chl/carotenoids ratio between 2.5 and 3.5 are usually a yellow- 
green colour, and these leaves are experiencing senescence progress [85]. All the centaury plants used in this study were grown in vitro. The addition of $\mathrm{NaCl}$ in the medium reduced the $\mathrm{Chl} /$ carotenoids ratio in the centaury shoots. In the non-transformed shoots, in the range of the $\mathrm{NaCl}$ concentrations, the $\mathrm{Chl} /$ carotenoids ratio ranged between 14.84 and 1.61; in the transgenic line AtCKX1-29, the detected ratio was 18.05-1.22; in AtCKX2-17, 5.59-1.10; and in AtCKX2-26, 16.49-1.30. Based on the value of the Chl/carotenoids ratio in the non-transformed and $A t C K X$ centaury plants grown in the $\mathrm{NaCl}$-free medium, it can be assumed that the transgenic plants had a delayed senescence. Previous investigations have shown that the transgenic AtCKX leaves of $A$. thaliana and tobacco remained green even longer than the leaves of the non-transformed plants and, consequently, did not show an accelerated but, contrary to expectations, showed a delayed senescence [28,49]. Obviously, the decrement of CKs is certainly one of the preconditions, but not the initial signal, for the beginning of senescence. On the other hand, a decreased value of the $\mathrm{Chl} /$ carotenoids ratio in the non-transformed, as well as in the transgenic $A t C K X$, centaury shoots grown in a range of $\mathrm{NaCl}$ concentrations could be an indicator of accelerating the senescence process in the salt stress conditions. The increased values of the $\mathrm{Chl} a / \mathrm{Chl} b$ ratio and, at the same time, decreased value of the weight $\mathrm{Chl} /$ carotenoids ratio are caused by the high irradiance adaptation response of the photosynthetic pigment apparatus of sun leaves [86].

\section{Conclusions}

Non-transformed and transgenic AtCKX centaury lines have different photosynthetic pigment contents as a response to salt stress conditions. Contrary to the theoretical expectations, the transgenic AtCKX centaury leaves did not show accelerated senescence, although the photosynthetic pigment contents decreased with the increasing salinity in the culture media. According to our results, it is clear that a low content of CKs in transgenic AtCKX centaury lines has a very important role in the progression of salt-induced senescence, but it is not a major signal definitively triggering its onset. However, the effect of salinity on photosynthetic pigments is highly specific and certainly requires additional investigation in order to provide an improved understanding of the pigment content variations among transgenic centaury plants.

Supplementary Materials: The following are available online et https:/ /www.mdpi.com/article/ 10.3390/agronomy11102056/s1, Table S1: Photosythetic pigments ratios in the shoots of nontransformed and AtCKX transgenic centaury lines after 8 weeks of growth in 1/2MS medium supplemented with graded $\mathrm{NaCl}$ concentration. The data represent the mean \pm standard error. Means marked with a different letter significantly different from the control, according to the LSD test $(p \leq 0.05)$.

Author Contributions: M.T.-M. contributed to all the in vitro experiments and manuscript preparation. S.M. and M.M. contributed to all the experimental work considering the photosynthetic pigments analyses. M.Đ. contributed to all the data analyses. S.J. and I.Č.D. contributed to the results interpretation. A.R.S. supervised the whole study and also contributed to preparing the final manuscript. All authors have read and agreed to the published version of the manuscript.

Funding: This work was supported by the Ministry of Education, Science and Technological Development of the Republic of Serbia, contract numbers 451-03-9/2021-14/200007 and 451-03-9/2021$14 / 200178$.

Institutional Review Board Statement: Not applicable.

Informed Consent Statement: Not applicable.

Data Availability Statement: All the data are in the manuscript.

Conflicts of Interest: The authors declare no conflict of interest. 


\section{References}

1. Simonović, A.D.; Trifunović-Momčilov, M.M.; Filipović, B.K.; Marković, M.P.; Bogdanović, M.D.; Subotić, A.R. Somatic embryogenesis in Centaurium erythraea Rafn-Current status and perspectives: A review. Plants 2021, 10, 70. [CrossRef]

2. Majeed, A.; Nisar, M.F.; Hussain, K. Effect of saline culture on the concentration of $\mathrm{Na}^{+}, \mathrm{K}^{+}$and $\mathrm{Cl}^{-}$in Agrostis tolonifera. Curr. Res. J. Biol. Sci. 2010, 2, 76-82.

3. Li, W.; Li, Q. Effect of environmental salt stress on plants and the molecular mechanism of salt stress tolerance. Int. J. Environ. Sci. Nat. Res. 2017, 7, 555714. [CrossRef]

4. Singhal, R.K.; Saha, D.; Skalicky, M.; Mishra, U.N.; Chauhan, J.; Behera, L.P.; Lenka, D.; Chand, S.; Kumar, V.; Dey, P.; et al. Crucial cell signaling compounds crosstalk and integrative multi-omics techniques for salinity stress tolerance in plants. Front. Plant Sci. 2021, 670369. [CrossRef] [PubMed]

5. Kwon, O.K.; Mekapogu, M.; Kim, K.S. Effect of salinity stress on photosynthesis and related physiological responses in carnation (Dianthus caryophyllus). Hortic. Environ. Biotechnol. 2019, 60, 831-839. [CrossRef]

6. Hajihashemi, S.; Brestic, M.; Kalaji, H.M.; Skalicky, M.; Noedoost, F. Environmental pollution is reflected in the activity of the photosynthetic apparatus. Photosyhthetica 2020, 58, 529-539. [CrossRef]

7. Turan, S.; Tripathy, B.C. Salt-stress induced modulation of chlorophyll biosynthesisduring de-etiolation of rice seedlings. Physiol. Plant. 2015, 153, 477-491. [CrossRef]

8. Ahanger, M.A.; Qi, C.; Maodong, Q.; Dong, X.X.; Ahmad, P.; Fathi, E.; Allah, A.; Zhang, L. Spermine application alleviates salinity induced growth and photosynthetic inhibition in Solanum lycopersicum by modulating osmolyte and secondary metabolite accumulation and differentially regulating antioxidant metabolism. Plant Physiol. Bioch. 2019, 144, 1-13. [CrossRef] [PubMed]

9. Rady, M.M.; Taha, R.S.; Mahdi, A.H. Proline enhances growth, productivity and anatomy of two varieties of Lupinus termis L. grown under salt stress. S. Afr. J. Bot. 2016, 102, 221-227. [CrossRef]

10. Yang, Z.; Li, J.-L.; Liu, L.-N.; Xie, Q.; Sui, N. Photosynthetic regulation under salt stress and salt-tolerance mechanism of sweet sorghum. Front. Plant Sci. 2020, 10, 1722. [CrossRef]

11. Rao, G.G.; Rao, G.R. Pigment composition chlorophyllase activity in pigeon pea (Cajanus indicus Spreng) and Gingelley (Sesamum indicum L.) under $\mathrm{NaCl}$ salinity. Indian J. Exp. Biol. 1981, 19, 768-770.

12. Ali, Y.; Aslam, Z.; Ashraf, M.Y.; Tahir, G.R. Effect of salinity on chlorophyll concentration, leaf area, yield and yield components of rice genotypes grown under saline environment. Int. J Environ. Sci. Technol. 2004, 1, 221-225. [CrossRef]

13. Lichtenthaler, H.K.; Langsdorf, G.; Lenk, S.; Bushmann, C. Chlorophyll fluorescence imaging of photosynthetic activity with the flesh lamp fluorescence imaging system. Phtosynthetica 2005, 43, 355-369. [CrossRef]

14. Molazem, D.; Qurbanov, E.M.; Dunyamaliyev, S.A. Role of proline, Na and chlorophyll content in salt tolerance of corn (Zea mays L.). Amer. Eurasian J. Agric. Environ. Sci. 2010, 9, 319-324.

15. Sevengor, S.; Yasar, F.; Kusvuran, S.; Ellialtıoglu, S. The effect of salt stress on growth, chlorophyll content, lipid peroxidation and antioxidative enzymes of pumpkin seedling. Amer. J. Agri. Res. 2011, 6, 4920-4924. [CrossRef]

16. Akca, Y.; Samsunlu, E. The effect of salt stress on growth, chlorophyll content, proline and nutrient accumulation, and K/Na ratio in in walnut. Pak. J. Bot. 2012, 44, 1513-1520.

17. Zhani, K.; Mariem, B.F.; Fardaous, M.; Cherif, H. Impact of salt stress ( $\mathrm{NaCl})$ on growth, chlorophyll content and fluorescense of Tunusian cultivars of chili pepper (Capsicum frutescens L.). J. Stress Physiol. Biochem. 2012, 8, 236-252.

18. Taibi, K.; Taibi, F.; Abderrahim, L.A.; Ennajah, A.; Belkhodja, M.; Mulet, J.M. Effect of salt stress on growth, chlorophyll content, lipid peroxidation and antioxidant defence systems in Phaseolus vulgaris L. S. Afr. J. Bot. 2016, 105, 306-312. [CrossRef]

19. Yarsi, G.; Sivaci, A.; Dasgan, H.Y.; Altuntas, O.; Binzet, R.; Akhoundnejad, Y. Effects of salinity stress on chlorophyll and carotenoid contents and stomata size of grafted and ungrafted galia c8 melon cultivar. Pak. J. Bot. 2017, 49, 421-426.

20. Fatehi, S.F.; Oraei, M.; Gohari, G.; Akbari, A.; Faramarzi, A. Proline-functionalized graphene oxide nanoparticles (GO-Pro NPs) mitigate salt-induced adverse effects on morpho-physiological traits and essential oils constituents in Moldavian Balm (Dracocephalum moldavica L.). J. Plant Growth Regul. 2021, 1-5. [CrossRef]

21. Parida, A.K.; Das, A.B. Salt tolerance and salinity effects on plants: A review. Ecotoxicol. Environ. Saf. 2005, 60, 324-349. [CrossRef]

22. Kubo, M.; Kakimoto, T. The cytokinin-hypersensitive genes of Arabidopsis nega-tively regulate the cytokinin-signaling pathway for cell division and chloroplast development. Plant J. 2000, 23, 385-394. [CrossRef]

23. Kulaeva, O.N.; Burkhanova, E.A.; Karavaiko, N.N.; Selivankina, S.Y.; Porfirova, S.A.; Maslova, G.G.; Zemlyachenko, Y.V.; Börner, T. Chloroplasts affect the leaf response to cytokinin. J. Plant Physiol. 2002, 159, 1309-1316. [CrossRef]

24. Cortleven, A.; Noben, J.P.; Valcke, R. Analysis of the photosynthetic apparatus in trans-genic tobacco plants with altered endogenous cytokinin content. Proteome. Sci. 2011, 9, 33. [CrossRef] [PubMed]

25. Cortleven, A.; Schmülling, T. Regulation of chloroplast development and function by cytokinin. J. Exp. Bot. 2015, 66, 4999-5013. [CrossRef] [PubMed]

26. Gan, S.; Amasino, R. Making sense of senescence (Molecular genetic regulation and manipulation of leaf senescence). Plant Physiol. 1997, 113, 313-319. [CrossRef] [PubMed]

27. Werner, T.; Motyka, V.; Strnad, M.; Schmülling, T. Regulation of plant growth by cytokinin. Proc. Natl. Acad. Sci. USA 2001, 98 , 10487-10492. [CrossRef] 
28. Werner, T.; Motyka, V.; Laucou, V.; Smets, R.; Van Onckelen, H.; Schmülling, T. Cytokinin-defcient transgenic Arabidopsis plants show multiple developmental alterations indicating opposite functions of cytokinins in the regulation of shoot and root meristem activity. Plant Cell 2003, 15, 2532-2550. [CrossRef] [PubMed]

29. Hartmann, A.; Senning, M.; Hedden, P.; Sonnewald, U.; Sonnewald, S. Reactivation of meristem activity and sprout growth of potato tubers require both cytokinin and gibberellin. Plant Physiol. 2011, 155, 776-796. [CrossRef] [PubMed]

30. Raspor, M.; Motyka, V.; Žižková, E.; Dobrev, P.I.; Trávníčková, A.; Zdravković-Korać, S.; Simonović, A.; Ninković, S.; Dragićević, I.Č. Cytokinin profles of AtCKX2-overexpressing potato plants and the impact of altered cytokinin homeostasis on tuberization in vitro. J. Plant. Growth Regul. 2012, 31, 460-470. [CrossRef]

31. Raspor, M.; Motyka, V.; Ninković, S.; Malbeck, J.; Dobrev, P.I.; Zdravković-Korać, S.; Simonović, A.; Ćosić, T.; Cingel, A.; Savić, J.; et al. Overexpressing AtCKX1 in potato plants grown in vitro: The efects on cytokinin composition and tuberization. J. Plant. Growth Regul. 2021, 40, 37-47. [CrossRef]

32. Trifunović, M.; Motyka, V.; Cingel, A.; Subotić, A.; Jevremovićm, S.; Petrić, M.; Holík, J.; Malbeck, J.; Dobrev, P.I.; Dragićević, I.Č. Changes in cytokinin content and altered cytokinin homeostasis in AtCKX1 and AtCKX2-overexpressing centaury (Centaurium erythraea Rafn.) plants grown in vitro. Plant. Cell Tiss. Org. 2015, 120, 767-777. [CrossRef]

33. Nehnevajova, E.; Ramireddy, E.; Stolz, A.; Gerdemann-Knörck, M.; Novák, O.; Strnad, M.; Schmülling, T. Root enhancement in cytokinin-deficient oilseed rape causes leaf mineral enrichment, increases the chlorophyll concentration under nutrient limitation andenhances the phytoremediation capacity. BMC Plant. Biol. 2019, 19, 83. [CrossRef] [PubMed]

34. Zwack, P.J.; Rashotte, A.M. Cytokinin inhibition of leaf senescence. Plant. Signal. Behav. 2013, 8, e24737. [CrossRef] [PubMed]

35. Petropoulos, S.A.; Karkanis, A.; Martins, N.; Ferreira, I.C.F.R. Halophytic herbs of the Mediterranean basin: An alternative approach to health. Food Chem. Toxicol. 2018, 114, 155-169. [CrossRef] [PubMed]

36. Šiler, B.; Mišić, D.; Filipović, B.; Popović, Z.; Cvetić, T.; Mijović, A. Effects of salinity on in vitro growth and photosynthesis of common centaury (Centaurium erythraea Rafn.). Arc. Biol. Sci. 2007, 59, 129-134. [CrossRef]

37. Trifunović-Momčilov, M.; Paunović, D.; Milošević, S.; Marković, M.; Jevremović, S.; Dragićević, I.Č.; Subotić, A. Salinity stress response of non-transformed and AtCKX transgenic centaury (Centaurium erythraea Rafn.) shoots and roots grown in vitro. Ann. Appl. Biol. 2020, 177, 74-89. [CrossRef]

38. Trifunović, M.; Cingel, A.; Simonović, A.; Jevremović, S.; Petrić, M.; Dragićević, I.Č.; Motyka, V.; Dobrev, P.I.; Zahajská, L.; Subotić, A. Overexpression of Arabidopsis cytokinin oxidase/dehydrogenase genes AtCKX1 and AtCKX2 in transgenic Centaurium erythraea Rafn. Plant. Cell Tiss. Org. 2013, 115, 139-150. [CrossRef]

39. Murashige, T.; Skoog, F. A revised medium for rapid growth and bioassays with tobacco tissue cultures. Physiol. Plant. 1962, 15, 473-479. [CrossRef]

40. Lichtenthaler, H.K. Chlorophylls and carotenoids: Pigments of photosynthetic biomembranes. Methods Enzymol. 1987, 148, 350-382. [CrossRef]

41. Wilhelmová, N.; Procházková, D.; Macháčková, I.; Vágner, M.; Srbová, M.; Wilhelm, J. The role of cytokinins and ethylene in bean cotyledon senescence. The effect of free radicals. Biol. Plant. 2004, 48, 523-529. [CrossRef]

42. Jordi, W.; Schapendonk, A.; Davelaar, E.; Stoopen, G.M.; Pot, C.S.; De Visser, R.; Van Rhijn, J.A.; Gan, S.; Amasino, R.M. Increased cytokinin levels in transgenic $\mathrm{P}_{\mathrm{SAG} 12} \mathrm{IPT}$ tobacco plants have large direct and indirect effects on leaf senescence, photosynthesis and N partitioning. Plant. Cell Environ. 2000, 23, 279-289. [CrossRef]

43. Stessman, D.; Miller, A.; Spalding, M.; Rodermel, S. Regulation of photosynthesis during Arabidopsis leaf development in continuous light. Photosynth. Res. 2002, 72, 27-37. [CrossRef]

44. Jiao, D.; Ji, B.; Li, X. Characteristics of chlorophyll fluorescence and membrane-lipid peroxidation during senescence of flag leaf in different cultivars of rice. Photosynthetica 2003, 41, 33-41. [CrossRef]

45. Weng, X.Y.; Xu, H.X.; Jiang, D.A. Characteristics of gas exchange, chlorophyll fluorescence and expression of key enzymes in photosynthesis during leaf senescence in rice plants. J. Integr. Plant. Biol. 2005, 47, 560-566. [CrossRef]

46. Heidari, A.; Bandehagh, A.; Toorchi, M. Effects of $\mathrm{NaCl}$ stress on chlorophyll content and chlorophyll fluorescence in sunflower (Helianthus annuus L.) lines. Yyu. J. Agr. Sci. 2014, 24, 111-120. [CrossRef]

47. Hniličková, H.; Hnilička, F.; Martinková, J.; Kraus, K. Effects of salt stress on water status, photosynthesis and chlorophyll fluorescence of rocket. Plant. Soil Environ. 2017, 63, 362-367.

48. Najar, R.; Aydi, S.; Sassi-Aydi, S.; Zarai, A.; Abdelly, C. Effect of salt stress on photosynthesis and chlorophyll fluorescence in Medicago truncatula. Plant. Biosyst. 2018, 153, 88-97. [CrossRef]

49. Mýtinová, Z.; Haisel, D.; Wilhelmová, N. Photosynthesis and protective mechanisms during ageing in transgenic tobacco leaves with over-expressed cytokinin oxidase/dehydrogenase and thus lowered cytokinin content. Photosynthetica 2006, 44, 599-605. [CrossRef]

50. Conrad, K.; Motyka, V.; Schlüter, T. Increase in activity, glycosylation and expression of cytokinin oxidase/dehydrogenase during the senescence of barley leaf segments in the dark. Physiol. Plant. 2007, 130, 572-579. [CrossRef]

51. Evans, T.; Song, J.; Jameson, P.E. Micro-scale chlorophyll analysis and developmental expression of a cytokinin oxidase/dehydrogenase gene during leaf development and senescence. Plant. Growth Regul. 2012, 66, 95-99. [CrossRef]

52. Ciobanu, I.; Sumalan, R. The effects of the salinity stress on the growing rates and physiological characteristics to the Lycopersicum esculentum Specie. B. Uasvm. Horti. 2009, 66, 616-620. 
53. Li, P.; Zhu, Y.; Song, X.; Song, F. Negative effects of long-term moderate salinity and short-term drought stress on the photosynthetic performance of Hybrid Pennisetum. Plant. Physiol. Bioch. 2020, 155, 93-104. [CrossRef] [PubMed]

54. Nunes, C.; de Sousa, S.; da Silva, J.M.; Fevereiro, M.P.; da Silva, A.B. Physiological responses of the legume model Medicago truncatula cv. Jemalong to water deficit. Environ. Exp. Bot. 2008, 63, 289-296. [CrossRef]

55. Ashraf, M.; Harris, P.J.C. Photosynthesis under stressful environments: An overview. Photosynthetica 2013, 51, 163-190. [CrossRef]

56. Turan, M.A.; Kalkat, V.; Taban, S. Salinity-induced stomatal resistance, proline, chlorophyll and ion concentrations of bean. Int. J. Agric. Res. 2007, 2, 483-488. [CrossRef]

57. Cheruth, J.; Ragupathi, G.; Ashot, K.; Paramasivam, M.; Beemarao, S.; Rajaram, P. Interactive effects of triadimefon and salt stress on antioxidative status and ajmalicine accumulation in Catharanthus roseus. Acta Physiol. Plant. 2008, 30, 287-292. [CrossRef]

58. Taffouo, V.D.; Kouamou, J.K.; Ngalangue, L.M.T.; Ndjeudji, B.A.N.; Akoa, A. Effects of salinity stress on growth, ions partitioning and yield of some cowpea (Vigna ungiuculata L., walp.) cultivars. Int. J. Bot. 2009, 5, 135-143. [CrossRef]

59. Taffouo, V.D.; Wamba, O.F.; Yombi, E.; Nono, G.V.; Akoe, A. Growth, yield, water status and ionic distribution response of three bambara groundnut (Vigna subterranean (L.) verdc.) landraces grown under saline conditions. Int. J. Bot. 2010, 6, 53-58. [CrossRef]

60. Heidari, M. Effects of salinity stress on growth, chlorophyll content and osmotic components of two basil (Ocimum basilicum L.) genotypes. Afr. J. Biotechnol. 2012, 11, 379-384. [CrossRef]

61. Shin, Y.K.; Bhandari, S.R.; Cho, M.C.; Lee, J.G. Evaluation of chlorophyll fluorescence parameters and proline content in tomato seedlings grown under different salt stress conditions. Hortic. Environ. Biote. 2020, 61, 433-443. [CrossRef]

62. Rastogi, A.; Kovar, M.; He, X.; Zivcak, M.; Kataria, S.; Kalaji, H.M.; Skalicky, M.; Ibrahimova, U.F.; Hussain, S.; Mbarki, S.; et al JIP-test as a tool to identify salinity tolerance in sweet sorghum genotypes. Photosynthetica 2020, 58, 518-528. [CrossRef]

63. Zhou, M.; Wei, Y.; Wang, J.; Liang, M.; Zhao, G. Salinity-induced alterations in physiological and biochemical processes of blessed thistle and peppermint. J. Soil Sci. Plant. Nut. 2021, 1-14. [CrossRef]

64. Misra, A.N.; Sahu, S.M.; Misra, M.; Singh, P.; Meera, I.; Das, N.; Kar, M.; Sahu, P. Sodium chloride induced changes in leaf growth, and pigment and protein contents in two rice cultivars. Biol. Plant. 1997, 39, 257-262. [CrossRef]

65. Biswal, A.K.; Dilnawaz, F.; Ramaswamy, N.K.; David, K.A.V.; Misra, A.N. Thermoluminescence characteristics of sodium chloride salt-stressed Indian mustard seedlings. Luminescence 2002, 17, 135-140. [CrossRef]

66. Youssef, T.; Awad, M. Mechanisms of enhancing photosynthetic gas exchange in date palm seedlings (Phoenix dactylifera L.) under salinity stress by a 5-aminolevulinic acid-based fertilizer. J. Plant. Growth Regul. 2008, 27, 1-9. [CrossRef]

67. Khan, N.A. NaCl-inhibited chlorophyll synthesis and associated changes in ethylene evolution and antioxidative enzyme activities in wheat. Biol. Plant. 2003, 47, 437-440. [CrossRef]

68. Tort, N.; Turkyilmaz, B. A physiological investigation on the mechanisms of salinity tolerance in some barley culture forms. $J$. Forensic Sci. 2004, 27, 1-16. [CrossRef]

69. Upadhyay, R.K.; Panda, S.K. Salt tolerance of two aquatic macrophytes. Pistia stratiotes and Salvinia molesta. Biol. Plant. 2005, 49, 157-159. [CrossRef]

70. Mustard, J.; Renault, S. Response of red-osier dogwood (Cornus sericea) seedling to NaCl during the onset of bud break. Can. J. Bot. 2006, 84, 844-851. [CrossRef]

71. Sharma, P.K.; Hall, D.O. Interaction of salt stress and photoinhibition on photosynthesis in barley and sorghum. J. Plant. Physiol. 1991, 138, 614-619. [CrossRef]

72. Park, S.; Fischer, A.L.; Steen, C.J.; Iwai, M.; Morris, J.M.; Walla, P.J.; Niyogi, K.K.; Fleming, G.R. Chlorophyll-carotenoid excitation energy transfer in high-light-exposed thylakoid membranes investigated by snapshot transient absorption spectroscopy. J. Am. Chem. Soc. 2018, 140, 11965-11973. [CrossRef] [PubMed]

73. Hajihashemi, S.; Mbarki, S.; Skalicky, M.; Noedoost, F.; Raeisi, M.; Brestic, M. Effect of wastewater irrigation on photosynthesis, growth, and anatomical features of two wheat cultivars (Triticum aestivum L.). Water 2020, 12, 607. [CrossRef]

74. Caffarri, S.; Tibiletti, T.; Jennings, R.C.; Santabarbara, S. A comparison between plant photosystem I and photosystem II architecture and functioning. Curr. Protein Pept. Sci. 2014, 15, 296-331. [CrossRef] [PubMed]

75. Li, Y.; He, N.; Hou, J.; Xu, L.; Liu, C.; Zhang, J.; Wang, Q.; Zhang, X.; Wu, X. Factors influencing leaf chlorophyll content in natural forests at the biome scale. Front. Ecol. Evol. 2018, 6, 64. [CrossRef]

76. Lichtenthaler, H.K.; Buschmann, C.; Döll, M.; Fietz, H.J.; Bach, T.; Kozel, U.; Meier, D.; Rahmsdorf, U. Photosynthetic activity, chloroplast ultrastructure and leaf characteristics of high-light and low-light plants and of sun and shade leaves. Photosynth. Res. 1981, 2, 115-141. [CrossRef]

77. Bavani, M.R.Z.; Peyvast, G.; Ghasemnezhad, M.; Forghani, A. Assessment of genotypic variation in salt tolerance of pepper (Capsicum annuиm L.) cultivars using gas exchange characteristic, growth parameters and chlorophyll content. Southwest J. Hort. Biol. Environ. 2015, 6, 71-90.

78. Fang, Z.; Bouwkamp, J.; Solomos, T. Chlorophyllase activities and chlorophyll degradation during leaf senescence in nonyellowing mutant and wild type of Phaseolus vulgaris L. J. Exp. Bot. 1998, 49, 503-510. [CrossRef]

79. Franck, N.; Winkler, S.; Pastenes, C.; Infante, R. Acclimation to sun and shade of three accessions of the Chilean native berry-crop murta. Agroforest. Syst. 2007, 69, 215-229. [CrossRef]

80. Trouwborst, G.; Hogewoning, S.W.; Harbinson, J.; van Ieperen, W. Photosynthetic acclimation in relation to nitrogen allocation in cucumber leaves in response to changes in irradiance. Physiol. Plant. 2011, 142, 157-169. [CrossRef] 
81. Miersch, I.; Heise, J.; Zelmer, I.; Humbeck, K. Differential degradation of the photosynthetic apparatus during leaf senescence in barley (Hordeum vulgare L.). Plant. Biol. 2000, 2, 618-623. [CrossRef]

82. Mishev, K.; Stefanov, D.; Ananieva, K.; Slavov, C.; Ananiev, E.D. Different effects of dark treatment on pigment composition and photosystem I and II activities in intact cotyledons and primary leaves of Cucurbita pepo (zucchini). Plant. Growth Regul. 2009, 58, 61-71. [CrossRef]

83. Weaver, L.M.; Amasino, R.M. Senescence is induced in individually darkened Arabidopsis leaves, but inhibited in whole darkened plants. Plant. Physiol. 2001, 127, 876-886. [CrossRef] [PubMed]

84. Ananieva, K.; Ananiev, E.D.; Doncheva, S.; Georgieva, K.; Tzvetkova, N.; Kamínek, M.; Motyka, V.; Dobrev, P.; Gajdošová, S.; Malbeck, J. Senescence progression in a single darkened cotyledon depends on the light status of the other cotyledon in Cucurbita pepo (zucchini) seedlings: Potential involvement of cytokinins and cytokinin oxidase/dehydrogenase activity. Physiol. Plant. 2008, 134, 609-623. [CrossRef] [PubMed]

85. Lichtenthaler, H.K.; Buschmann, C. Chlorophylls and carotenoids: Measurement and characterization by UV-VIS spectroscopy. Curr. Prot. F. Anal. Chem. 2001, F4.3.1-F4.3.8. [CrossRef]

86. Lichtenthaler, H.K.; Babani, F.; Langsdorf, G. Chlorophyll fluorescence imaging of photosynthetic activity in sun and shade leaves of trees. Photosynth. Res. 2007, 93, 235-244. [CrossRef] 